\title{
声学超材料的机遇和挑战
}

\author{
刘晓峻
}

南京大学声学研究所, 南京 210093

E-mail: liuxiaojun@nju.edu.cn

\section{Opportunities and challenges of acoustic metamaterials}

\author{
Xiaojun Liu \\ Institute of Acoustics, Nanjing University, Nanjing 210093, China \\ E-mail: liuxiaojun@nju.edu.cn \\ doi: 10.1360/TB-2020-0300
}

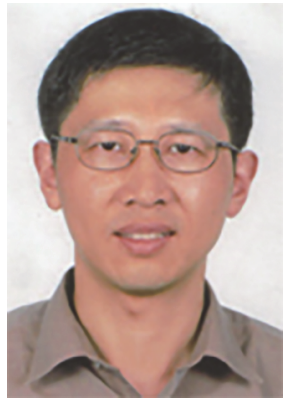

\section{刘獍峻}

近代声学教育部重点实验室 主任, 南京大学声学研究所所 长, 兼任中国声学学会常务理 事、检测声学分会副主任、江 苏省声学学会理事长。入选 2004 年度教育部新世纪优秀 人才培养计划, 2008 年享受国 务院政府特殊津贴。主要从事 声学人工材料及新原理声学 功能器件、光声光热效应及声 信号处理等方面的研究工作.
对声波的自由操控是声学基础研究的核心问题之一，也是声学成像、治 疗、探测、通信及对抗等应用领域的关键技术, 与国家重大需求密切相关, 例 如高精度声学成像、精准超声治疗及高容量声学通信等重要问题的解决都需 要以对声波实现精确及高效的操控为基础. 尽管声波已在诸多重要领域得到 广泛的应用, 但传统声学方法通常使用天然声学材料来实现不同的声波操控 及构建各种声学器件. 受限于天然材料自身的声学属性, 声操控理论与技术 的发展受到极大制约, 致使声学学科中存在低频声调控、复杂声场生成及非 对称声传输等难题, 简便、高效而精准的声波操控仍面临极大的挑战. 声学超 材料的出现赋予了声学学科一个全新的生命, 极大地促进了声学材料的发展 与进步. 相较于传统的声学材料, 声学超材料由于其具备传统材料所不具备 的超常物理性质, 使得多种新颖的声学现象和功能得以实现, 如声学负折射、 声隐身、声学亚波长成像、声学全息、声学完美吸收等等, 呈现出巨大的发 展潜力, 成为现代声学研究中一个非常前沿的领域.

近年来, 一大批国内学者在声学超材料研究领域崭露头角, 取得了一批 具有国际领先水平的研究成果. 为了帮助读者们系统地了解这一领域的前沿 发展, 《科学通报》邀请了部分活跃在这一领域的青年学者, 组织了“声学超 材料前沿与应用”专题, 从目前最前沿的拓扑声学超材料 ${ }^{[1]}$ 到最具应用前景的 水声超材料 ${ }^{[2]}$ 和低频吸声超材料 ${ }^{[3]}$ ，在基础理论和实验技术等诸多方面，阐 述了声学超材料的研究现状、前沿进展和未来展望. 希望本专题的文章能够 对声学超材料领域的学术交流有些许帮助, 为该研究领域的发展作一点贡献.

\section{参考文献}

1 Fan H Y, Xia B Z. Higher-order topological states in a three-dimensional acoustic metamaterial (in Chinese). Chin Sci Bull, 2020, 65: 1411-1419 [范海燕, 夏百战. 三维声学超材料的高阶拓扑态. 科学通报, 2020, 65: 1411-1419]

2 Zhang Y N, Chen K A, Hao X Y, et al. A review of underwater acoustic metamaterials (in Chinese). Chin Sci Bull, 2020, 65: 1396-1410 [张燕妮, 陈克安, 郝夏影, 等. 水声超材料研究进展. 科学通报, 2020, 65: 1396-1410]

3 Li D T, Huang S B, Mo F S, et al. Low-frequency broadband absorbers based on coupling micro-perforated panel and space-curling chamber (in Chinese). Chin Sci Bull, 2020, 65: 1420-1427 [李东庭, 黄思博, 莫方朔, 等. 基于微穿孔板和卷曲背腔复合结构的低频 宽带吸声体. 科学通报, 2020, 65: 1420-1427] 